\title{
ORIGINAL ARTICLE \\ Prevalence and associated factors of pain in the Swiss spinal cord injury population
}

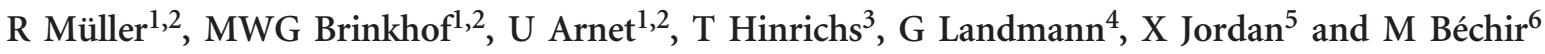 \\ for the SwiSCI Study Group
}

\begin{abstract}
Study design: Population-based, cross-sectional.
Objectives: To determine pain prevalence and identify factors associated with chronic pain in individuals with spinal cord injury (SCI) living in Switzerland.

Setting: Swiss SCl Cohort Study (SwiSCl).

Methods: Pain characteristics were assessed using an adapted version of the International SCI Pain Basic Data Set, adding one item of the SCI Secondary Conditions Scale to address chronic pain. Pain prevalence was calculated using stratification over demographic, $\mathrm{SCl}$-related and socioeconomic characteristics; odds ratios (adjusted for non-response) for determinants of severity of chronic pain were calculated using stereotype logistic regressions.
\end{abstract}

Results: Pain (in the past week) was reported by $68.9 \%$ and chronic pain by $73.5 \%$ (significant $36.9 \%$ ) of all participants $(N=1549$; $28 \%$ female). Most frequently reported pain type was musculoskeletal $(71.1 \%)$. Back/spine was the most frequently reported pain location (54.6\%). Contrasting the 'significant' to the 'none/mild' category of chronic pain, adjusted odds ratios were $1.54(95 \% \mathrm{Cl}$ : $1.18-2.01 ; P<0.01)$ for women (vs men); 6.64 (95\% Cl: 3.37-11.67; $P<0.001$ ) for the oldest age group 61+ (vs youngest (16-30)); 3.41 (95\% Cl: 2.07-5.62; $P<0.001)$ in individuals reporting severe financial hardship (vs no financial hardship). Individuals reporting specific SCl-related health conditions were 1.41-2.92 $(P<0.05)$ times more likely to report chronic pain as 'significant' rather than 'none/mild' compared with those without the respective condition.

Conclusions: Pain is highly prevalent in individuals with SCl living in Switzerland. Considered at risk for chronic pain are women, older individuals and individuals with financial hardship and specific secondary health conditions. Longitudinal studies are necessary to identify predictors for the development of pain and its chronification.

Spinal Cord (2017) 55, 346-354; doi:10.1038/sc.2016.157; published online 15 November 2016

\section{INTRODUCTION}

Chronic pain is a significant problem in individuals with a spinal cord injury (SCI) that can have a negative impact on a person's physical, psychological and social functioning. ${ }^{1}$ Pain prevalence in SCI range around $61 \%( \pm 20 \%){ }^{2}$ Most prevalent pain types are musculoskeletal pain most frequently localized to the neck, shoulders and back, and neuropathic pain usually localized to the front torso, buttocks and lower extremities. ${ }^{3}$ About one-third of persons with SCI report experiencing severe pain. ${ }^{4}$ Longitudinal pain research further exposed a cumulative risk with time since injury ${ }^{2}$ and importantly, that an established pain problem rarely resolves. ${ }^{1}$ Chronic pain in SCI may further vary with gender (for example, refs 5-8), current age (for example, refs 6-8), lesion etiology, ${ }^{9}$ level (for example, refs 5 , 6 and 10) and completeness. ${ }^{7,8}$ Education, ${ }^{10,11}$ financial problems ${ }^{12}$ and secondary health complications (for example, spasticity, ${ }^{13,14}$ fractures, ${ }^{15}$ infections ${ }^{16}$ and autonomic dysreflexia ${ }^{17}$ ) may be further factors associated with pain. However, these findings are inconsistent and have limited generalizability as they depend on study design-related information such as (chronic) pain definition, primary study goal, data source and quality. 2,18

In Switzerland, pain has been reported as one of the most burdensome consequences of SCI. ${ }^{19}$ A previously found high prevalence of chronic SCI pain (73.2\%) in the Swiss SCI community ${ }^{20}$ demands for more comprehensive research to provide detailed information on severity of pain, pain chronification, type and location, as well as person-related, injury-related and socioeconomic factors associated with pain prevalence. Findings from the present study are important not only to confirm the serious nature of pain in individuals with SCI but also to provide information for the development of effective treatments for SCI pain and to further support and inform SCI rehabilitation and research, the Swiss health-care system and policy making.

Therefore, the objective of the present study is to determine pain prevalence and to identify factors associated with chronic pain in individuals with SCI living in Switzerland. The following specific questions are addressed: (1) what is the proportion of persons

${ }^{1}$ Empowerment, Participation and Social Integration Unit, Swiss Paraplegic Research (SPF), Nottwil, Switzerland; ${ }^{2}$ Department of Health Sciences and Health Policy, University of Lucerne, Lucerne, Switzerland; ${ }^{3}$ Division of Sports and Exercise Medicine, Department of Sport, Exercise and Health, University of Basel, Basel, Switzerland; ${ }^{4}$ Centre for Pain Medicine, Swiss Paraplegic Centre, Nottwil, Switzerland; ${ }^{5}$ Clinique Romande de Réadaptation, Sion, Switzerland and ${ }^{6}$ Department of Intensive Care, Pain and operative Medicine, Swiss Paraplegic Centre, Nottwil, Switzerland

Correspondence: Dr R Müller, Empowerment, Participation and Social Integration Unit, Swiss Paraplegic Research (SPF), Guido A. Zäch-Strasse 4, 6207 Nottwil, Switzerland. E-mail: rachel.mueller@paraplegie.ch

Received 10 May 2016; revised 25 July 2016; accepted 6 October 2016; published online 15 November 2016 
reporting (a) pain in the past week and (b) a chronic pain problem? (2) How severe is the pain? (3) What types and locations of pain are reported and what are their relative frequencies? (4) How does the severity of chronic pain vary depending on person-, injury-related and socioeconomic characteristics, and secondary health conditions?

\section{METHODS}

\section{Study design and procedures}

This study analyses cross-sectional survey data collected between late 2011 and early 2013 within the community-based Swiss Spinal Cord Injury (SwiSCI) Cohort Study. ${ }^{21}$ SwiSCI is conducted in collaboration with the four specialized SCI rehabilitation clinics in Switzerland with the aim to include all individuals 16 years of age or older with permanent residence in Switzerland and a diagnosed traumatic or non-traumatic SCI. Individuals with congenital conditions resulting in para- or tetraplegia are excluded (for example, spina bifida, new SCI in the context of palliative care, neurodegenerative disorders including multiple sclerosis and amyotrophic lateral sclerosis or Guillain-Barré syndrome). SwiSCI adheres to the national and international standards for research in humans and received approval by the cantonal ethical committee. All participants provided written informed consent. The study protocol, design, procedure and data quality of SwiSCI is described in more detail elsewhere. ${ }^{22,23}$

Eligible participants completed self-report questionnaires sent by mail, via online secure server or telephonic interview. In the first wave, participants were asked to complete a short questionnaire about person-related, injury-related and socioeconomic characteristics. Participants who consented and completed the first questionnaire received a second-wave questionnaire about health, functioning, participation and well-being. A total of 1549 individuals out of 3144 potential participants completed the second-wave questionnaire, corresponding to a cumulative response rate of $49.3 \%$ and displaying marginal non-response bias. ${ }^{23}$ For this study, data from the first- and the second-wave questionnaire were analyzed.

\section{Variable and instruments}

Person-related and injury-related information (gender, age, lesion severity, etiology and time since injury), socioeconomic characteristics (language, education, financial hardship and income) and secondary health conditions were assessed and grouped based on recommendation of the International Spinal Cord Society. ${ }^{24,25}$ Secondary health conditions were assessed using the Spinal Cord Injury Secondary Conditions Scale, which has been found to be a reliable and valid measure to assess 15 most frequently occurring secondary health conditions in SCI that can be directly and indirectly associated with health and physical functioning. ${ }^{26}$ The present study focused on health conditions found to be most strongly related to pain (spasticity, contractures, autonomic dysreflexia, urinary tract infection and pressure ulcer). Language of correspondence (that is, German, French and Italian) was used as proxy for cultural setting, ${ }^{27}$ since inclusion of Nationality as potential factor was not possible due to high representation of Swiss Nationality (Swiss 90\%, Italian $2.4 \%$, German 1.0\%, French, Kosovan, Portuguese and Austrian between 0.5 and $0.7 \%$ ). With regards to financial hardship participants were asked to indicate the impact of potential financial difficulties in everyday life experienced over the past 4 weeks ('not applicable', 'had no impact', 'has complicated my life somewhat' and 'has complicated my life immensely'). ${ }^{12}$ The first two response categories were combined in order to derive a three-categorical variable for further analyses (that is 'no difficulties', 'some difficulties' and 'many difficulties').

Pain characteristics were assessed by applying an adapted version of the International Spinal Cord Injury Pain Basic Data Set. ${ }^{28}$ Participants were asked to indicate if they experienced pain in the past week with response options 'yes' or 'no'. If yes, respondents were invited to specify one or more pain types including musculoskeletal pain, visceral pain, pain due to spasms, neuropathic pain above lesion level, neuropathic pain at lesion level, neuropathic pain below lesion level and others. For better understanding of the pain type, synonyms and examples were added to each listed type of pain (for example, 'neuropathic pain, or nerve pain, phantom limb pain'). Participants were further asked to indicate average pain intensity in the past week on a 1-10 numeric rating scale (NRS) ranging from 1 signifying 'no pain' to 10 implying 'pain as bad as you can imagine'. With regards to the body locations affected by pain, participants were asked to select areas of pain from a list including neck, shoulder, back/spine, elbow, wrist/hands, hip(s), bottom, knee (s), ankle joint/food or in case any other regions (as free text).

To also address pain as a chronic problem, an additional item of the Spinal Cord Injury Secondary Conditions Scale ${ }^{26}$ was used. Respondents were asked to indicate on a four-point Likert-scale the perceived frequency and severity of chronic pain in the past 3 months ('not existing or insignificant problem' (no), 'mild or infrequent problem' (mild), 'moderate or occasional problem' (moderate), or 'significant or chronic problem' (significant)).

\section{Analyses}

Statistics to describe the total sample's characteristics were performed in PASW Statistics (Version 18.0 for Windows, SPSS Inc, Chicago, IL, USA) and Stata (Version 13.1 for Windows, College Station, TX, USA). Findings were reported stratified by pain in the past week and chronic pain severity. Sensitivity analyses were based on comparing descriptive statistics of the total sample with potential sample outliers (that is participants who indicated having no pain in the past week but reported a significant chronic pain problem $(n=18))$. No substantial discrepancies concerning person-, injury-related and socioeconomic characteristics were apparent, although selected outliers were more frequently found in the older age group $(61+)$.

To determine the prevalence of pain in the past week and chronic pain problem frequencies and percentages were computed. With regards to chronic pain, percentages of individuals experiencing chronic pain as 'no', 'mild', 'moderate' or 'significant' problem were calculated. Mean and standard deviation of pain intensity was computed. In addition, percentages in mild (NRS: 1-3), moderate (NRS: 4-6) and severe pain (NRS: 7-10 ${ }^{29}$ were calculated. Pain type and location were addressed by calculating percentages in addition to mean and range of number of pain types and locations.

Associations across the ordinal severity levels of chronic pain with independent variables, including person-, injury-related and socioeconomic characteristics, and secondary health conditions (specific aim 4) were examined in a final step. Use of Brant test ${ }^{30}$ indicated for the majority of independent variables that the proportional odds assumption was violated, implying that the relationship between each pair of response categories was not appropriately described by enforcing a common set of coefficients. Stereotype logistic regression provides a flexible alternative method that also enforces ordering constraints, but with the distinction that effects of each independent predictor variable may vary across pairs of response categories, implying pair-specific sets of coefficients. Model complexity can further be reduced by using constraints that impose the joint estimation of coefficient sets for adjacent response categories that are indistinguishable. ${ }^{31}$ Stereotype logistic regression thus estimates the odds of being in any particular category compared with the preset baseline category, here the 'no/mild (chronic pain) problem' category. The first two categories of the ordinal scale including 'not existing or insignificant problem' (no), and 'mild or infrequent problem' (mild) appeared as indistinguishable (adjusted Wald test, $\mathrm{F}(1,1548)=2.60 ; P=0.11$ ). Enforcing a corresponding constraint effectively reduced the outcome scale for chronic pain to a three-level ordinal variable ('no or mild problem' (no/mild), 'moderate problem' (moderate), 'significant problem' (significant)) in the analyses.

Adjusted odds ratios for being in a given chronic pain level group as compared with being in consecutively lower pain level groups for predictor variables were derived from multivariable modeling using three regression models. Model 1 included basic demographics (that is, gender and age group), as well as SCI-related variables (that is, lesion severity, etiology and time since injury). Model 2 additionally included specific socioeconomic variables, comprising language, education, financial hardship and net equivalent income. Model 3 included concurrent SCI-specific secondary health conditions, that is, spasticity, contractures, autonomic dysreflexia, urinary tract infection and pressure ulcer, and was adjusted for variables in Model 1 only. Model 2 variables were not included into Model 3 as it goes beyond this paper to evaluate and account for the potential causal pathways between self-reported socioeconomic variables and secondary health conditions in regression modeling. 


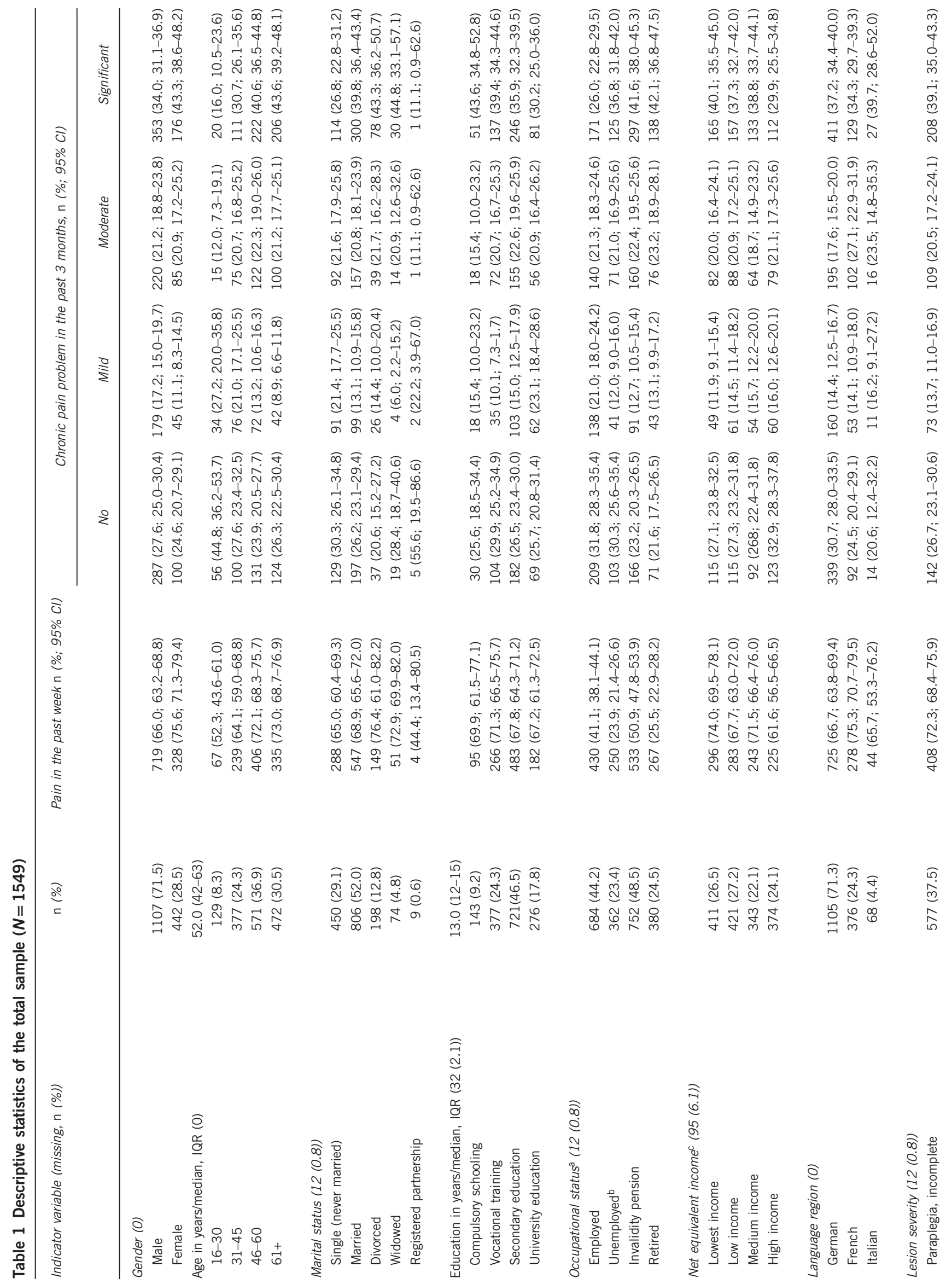


Global significance testing using Wald tests was applied to derive $P$-values in multivariable modeling. For categorical parameters with more than two levels that showed global alpha $\leqslant 5 \%$, the distinguishability of parameter levels was evaluated using pairwise comparisons, implementing Bonferroni correction of $P$-values as to account for multiple testing (that is, the number of unplanned post-hoc estimations). To visually illustrate the predicted distribution of participants over the ordinal levels of chronic pain, marginal predictions at means from the final multivariable regression model were used.

Finally, to draw near population-based conclusions, potential unit non-response bias was accounted for by applying inverse probability weighing based on propensity scores from multivariate logistic regression (for more details see Fekete et al. ${ }^{23}$ ). With regards to item non-response, descriptive analyses were performed on the complete case data reporting percentage of missing data; however, for the stereotype logistic regressions multiple imputation was performed using random forest imputation technique (R-package missForest ${ }^{32}$ ).

\section{RESULTS}

Table 1 shows that participants were mostly male (72\%), with a median age of 52 years (interquartile range: 42-63) and living on an average since 17 years (interquartile range: $0.3-76$ ) with a traumatic SCI $(78 \%)$ and a paraplegia (complete $32 \%$, incomplete $38 \%$ ) in the German speaking area of Switzerland (71\%). Women more frequently reported pain in the past week and experiencing pain as a significant chronic problem in the past 3 months. Percentage of individuals reporting a significant chronic pain problem increases with age. Highest percentages of participants reporting a significant chronic pain problem were found in individuals who are divorced or widowed, within the lowest level of education, with a middle income, a non-traumatic paraplegia and a time since injury range of 6-15 years (Table 1).

As shown in Table 2, a proportion of $68.9 \%$ (95\% CI: 66.4-71.2) reported pain in the past week. With regards to chronic pain, $36.9 \%$ (95\% CI: 34.3-39.5) reported a significant, $21.0 \%$ (95\% CI: $18.9-23.2$ ) a moderate, $15.6 \%$ (95\% CI: $13.7-17.6)$ a mild and $26.5 \%(95 \% \mathrm{CI}$ : 24.3-28.9) no chronic pain problem (chronic pain total $=73.5 \%$ ). Average pain intensity in the past week was $6( \pm 2)$ on a 1-10 NRS. Severe pain (NRS: 7-10) was reported by $40.6 \%$ (95\% CI: 37.5-43.7), moderate pain (NRS: $4-6$ ) by $43.6 \%$ (95\% CI: 40.4-46.6) and mild pain (NRS: $1-3$ ) by $15.9 \%$ (95\% CI: 13.7-18.3). Participants reported on an average two different pain types (range: $1-7$ ). Most frequently reported pain types were musculoskeletal pain $(71.1 \%$ (95\% CI: 68.2-37.8)), followed by neuropathic pain beneath lesion level (41.6\% (95\% CI: 38.6-44.7)) and visceral pain (25.3\% (95\% CI: 22.7-28.1)). Participants reported on average four different pain locations (range: 1-12). Back/spine (54.6\% (95\% CI: 51.4-57.6)), shoulder $(50.0 \%$ (95\% CI: 46.9-53.1)) and neck (43.2\% (95\% CI: 40.2-46.3)) were the most frequently reported areas affected by pain.

Stereotype logistic regression (Table 3 ) indicated that the severity of chronic pain varies depending on gender, age, financial hardship and the reporting of the secondary health complications spasticity, contractures, autonomic dysreflexia, urinary tract infection and pressure ulcer. More specifically, women were found to have 1.54 (95\% CI: $1.18-2.01 ; P<0.01)$ times higher odds than men to be in the 'significant' chronic pain problem category as compared with the 'no/mild' category. Highest odds to report a significant chronic pain problem were found in the oldest age group (6.64 (95\% CI: 3.37-11.67; $P<0.001)$ ) and in individuals reporting many financial difficulties (3.41 (95\% CI: 2.07-5.62; $P<0.001)$ ). Individuals with spasticity $(2.38$ (95\% CI: $1.76-3.21 ; P<0.001))$, contractures $(2.92$ (95\% CI: $2.22-3.83 ; P<0.001)$ ), autonomic dysreflexia $(2.56$ (95\% CI: $1.85-3.54 ; \quad P<0.001)$ ), urinary tract infections $(1.59$ (95\% CI: 
Table 2 Descriptive statistics for pain parameters, including frequencies, proportions and adjusted proportions (Total $N=1549)$

\begin{tabular}{|c|c|c|c|c|}
\hline \multirow[t]{2}{*}{ Indicator variable } & Frequency & Missing & Proportion (\%) & Adjusted proportion (\%) \\
\hline & $\mathrm{n}$ & n (\%) & $(95 \% \mathrm{Cl})$ & $(95 \% \mathrm{Cl})$ \\
\hline Pain in the past week & & $26(1.7)$ & & \\
\hline Yes & 1047 & & $68.7(66.4-71.0)$ & $68.9(66.4-71.2)$ \\
\hline No & 476 & & $31.2(29.0-33.6)$ & $31.1(28.8-33.6)$ \\
\hline Chronic pain problem in the last 3 months & & $104(6.7)$ & & \\
\hline Significant & 529 & & $36.6(34.6-39.1)$ & $36.9(34.3-39.5)$ \\
\hline Moderate & 305 & & $21.1(19.1-23.3)$ & $21.0(18.9-23.2)$ \\
\hline Mild & 224 & & $15.5(13.7-17.4)$ & $15.6(13.7-17.6)$ \\
\hline No & 387 & & $26.8(24.6-29.1)$ & $26.5(24.3-28.9)$ \\
\hline Mean pain severityb,c/mean (s.d.): $5.8(2.0)$ & & $42(4.0)$ & & \\
\hline Severe pain (NRS: 7-10) & 410 & & $40.8(37.8-43.9)$ & $40.6(37.5-43.7)$ \\
\hline Moderate pain (NRS: 4-6) & 436 & & $43.4(40.3-46.5)$ & $43.6(40.4-46.6)$ \\
\hline Mild pain (NRS: 1-3) & 159 & & $15.8(13.7-18.2)$ & $15.9(13.7-18.3)$ \\
\hline Type of pain b,d/mean (s.d.), range: $2.1(1.2), 1-7$ & & $12(1.1)$ & & \\
\hline Musculoskeletal pain & 766 & & $71.4(68.6-74.0)$ & $71.1(68.2-73.8)$ \\
\hline Neuropathic pain beneath lesion level & 455 & & $42.4(39.5-45.4)$ & $41.6(38.6-44.7)$ \\
\hline Visceral pain & 276 & & $25.7(23.2-28.4)$ & $25.3(22.7-28.1)$ \\
\hline Due to spasm & 253 & & $23.6(21.1-26.2)$ & $23.5(20.1-26.2)$ \\
\hline Neuropathic pain at lesion level & 214 & & $19.9(17.7-22.4)$ & $19.8(17.5-22.4)$ \\
\hline Neuropathic pain above lesion level & 133 & & $12.4(10.6-14.5)$ & $12.3(10.4-14.5)$ \\
\hline Other pain type & 108 & & $10.0(8.4-12.0)$ & $10.5(8.8-12.6)$ \\
\hline Pain locationd/mean (s.d.), range: 3.5 (2.0), 1-12 & & $21(2.0)$ & & \\
\hline Back/spine & 583 & & $54.3(51.3-57.3)$ & $54.6(51.4-57.6)$ \\
\hline Shoulder & 546 & & $50.9(47.9-53.9)$ & $50.0(46.9-53.1)$ \\
\hline Neck & 463 & & $43.2(40.2-46.1)$ & $43.2(40.2-46.3)$ \\
\hline Wrist/hands & 307 & & $28.6(26.0-31.4)$ & $28.0(25.4-30.9)$ \\
\hline Ankle joint/foot & 266 & & $24.8(22.3-27.5)$ & $26.0(23.3-28.8)$ \\
\hline Hip(s) & 263 & & $24.5(22.0-27.2)$ & $25.3(22.7-28.1)$ \\
\hline Bottom & 255 & & $23.8(21.3-26.4)$ & $23.8(21.3-26.6)$ \\
\hline Knee(s) & 217 & & $20.2(17.9-22.7)$ & $21.5(19.0-24.2)$ \\
\hline Elbow & 138 & & $12.9(11.0-15.0)$ & $12.5(10.6-14.6)$ \\
\hline No musculoskeletal pain & 38 & & $3.5(2.6-4.8)$ & $3.3(2.4-4.6)$ \\
\hline Other pain location & 115 & & $10.7(9.0-12.7)$ & $11.0(9.2-13.1)$ \\
\hline
\end{tabular}

Abbreviations: $\mathrm{Cl}$, confidence interval; NRS, numeric rating scale.

aproportion corrected for non-response.

bProportion and adjusted proportion refers to all individuals who indicated having pain in the past week $(n=1047)$.

cMean pain severity is based on all individuals who indicated having pain in the past week $(n=1047)$.

${ }^{d}$ More than one selection/specification possible.

$1.19-2.11 ; P<0.01))$ and pressure ulcer $(1.41$ (95\% CI: $1.04-1.91$; $P<0.05)$ ) had higher odds to report a significant chronic pain problem than participants reporting having no problem with these health conditions. Figure 1 illustrates these findings. No significant associations of chronic pain with lesion characteristics (that is, lesion severity, etiology and time since injury) were found.

\section{DISCUSSION}

This study determined a nearly $74 \%$ prevalence of chronic pain in individuals with SCI living in Switzerland. More than one-third reported a significant chronic pain problem. Participants reported on average two different pain types affecting four different body locations. Musculoskeletal pain was the most frequently reported pain type. Back/spine was the most frequently reported pain location. Chronic pain varied depending on gender, age, financial hardship and the reporting of secondary health complications including spasticity, contractures, autonomic dysreflexia, urinary tract infection and pressure ulcer.

Pain is a frequent and significant problem in individuals with SCI. Pain prevalence found in the present study lies within a range of
$41-81 \%$, which was documented by two systematic literature reviews on pain prevalence in SCI. This wide range reflects between-studies' heterogeneity (that is, different pain definitions, assessment, study design, population, data source and response rate). ${ }^{2,18}$ However, studies addressing prevalence of pain in a community setting are limited, although they provide valuable information on the extent of pain chronification. $1,33,34$

Diagnosis and differentiation of pain types are essential in order to target pain treatment. In general, musculoskeletal pain seems to be the most common type of pain, both in clinical (for example, due to trauma) and community settings (for example, due to overuse). ${ }^{13,35}$ Neuropathic pain at lesion level was found to develop shortly after injury compared with temporally delayed trajectory of below lesionlevel neuropathic pain (months to years after the injury), ${ }^{35}$ pointing at two different etiological pathways. In general, neuropathic pain early after injury likely predicts chronicity ${ }^{35}$ and is, with mostly unclear etiology, difficult to treat. ${ }^{36,37}$ In contrast, prediction of musculoskeletal pain based on the first 6 months seems unlikely, ${ }^{35}$ but when present, treatment options can be usually based on an underlying cause. Visceral pain was found to occur in every third person and half 
Table 3 Adjusted odds ratios of chronic pain comparing ordinal levels 'no/mild' (combined), 'moderate' and 'significant' as derived from stereotype logistic regression analysis

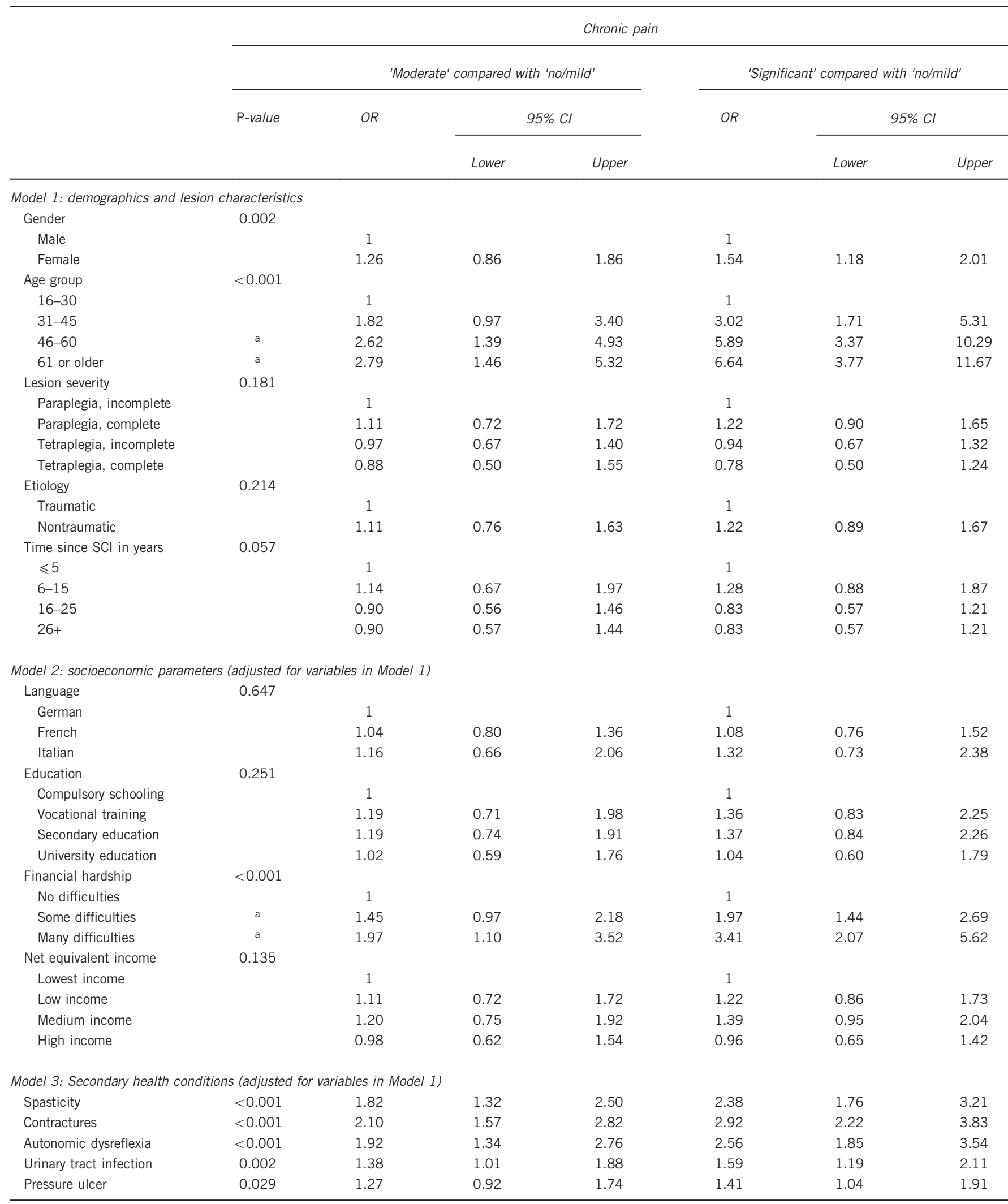

Abbreviations: $\mathrm{Cl}$, confidence interval; $\mathrm{SCl}$, spinal cord injury.

Estimates for presented variables in models with 'socioeconomic parameters' and 'health conditions' are controlled for all person- and injury-related characteristics.

a Pairwise comparison, Bonferroni-corrected $P<0.05$. 


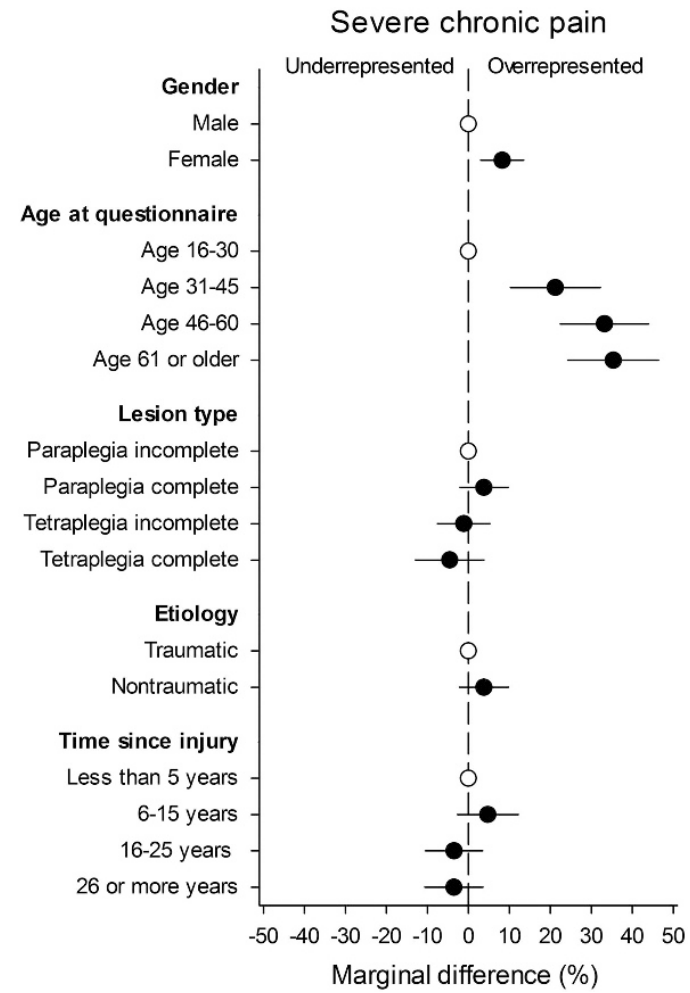

Figure 1 Marginal prediction of the distribution of participants over the ordinal levels of chronic pain for demographic and lesion parameters. Estimates are at mean values for other parameters using the stereotype logistic regression model in Table 3. Open symbols indicate the reference category for each parameter; solid symbols and error bars the percent difference with $95 \%$ confidence interval for other parameter classes.

of them reported an average onset later than 5 years after SCI. ${ }^{38,39}$ Etiologies have been suggested to be both central (for example, neuropathy) and peripheral (for example, chronic constipation) $;^{40,41}$ however, they mostly remain unclear. $^{42}$ Although prevalence of visceral pain is lower compared with other pain types, it is experienced as severe and excruciating. ${ }^{35,39}$

Not only multiple pain types but also an average of four different pain locations were reported by the majority of participants in the present study. These findings are in line with previous studies and underscore the importance of measuring pain intensity at all specific pain locations when attempting to explain the impact of pain on a person's functioning. ${ }^{39,43}$

The present study revealed women to have higher odds of chronic pain. Findings about gender and pain are inconsistent. A majority of studies in SCI found no differences between males and females concerning pain report. ${ }^{10,18,44}$ However, general research in women indicates that physiological (for example, anti-dopaminergic effect of estrogen), social (for example, being more inclined to report pain) and psychological factors (for example, higher prevalence of mood disorders) may contribute to a higher prevalence of pain in women compared with men. ${ }^{45}$

Older age was found as an additional factor associated with chronic pain, which is in line with research in aging ${ }^{46}$ and in specific aging with SCI. ${ }^{47,48}$ Aging with SCI is described as 'accelerated' in specific organ systems such as the musculoskeletal, endocrine and cardiovascular system. ${ }^{49-51}$ Disentanglement of age- and pain-specific conditions and identifying symptom clusters and mechanisms are challenging but fundamental components in the treatment of pain in individuals aging with SCI. ${ }^{48}$ Duration of injury has been identified as another temporal factor influencing pain. ${ }^{2}$ With a significance level of 0.057 , the present study indicates a tendency for time since injury to be a potential risk factor for chronic pain.

No association between lesion characteristics (that is, etiology, level and completeness) and pain was found in the present study, which is consistent with other studies summarized in a systematic literature review. ${ }^{18}$ However, with regards to neuropathic pain, findings are inconsistent. For example, two studies found complete lesion and tetraplegia to be associated with below lesion-level neuropathic pain. ${ }^{35,44}$ In contrast, a recent study revealed at lesion-level neuropathic pain to be more frequent in individuals with complete lesions. ${ }^{39}$ Although, in general, individuals with traumatic lesion etiology compared with non-traumatic etiology report more frequent complications and higher level of disability, ${ }^{52}$ findings with regards to pain are inconsistent. For example, in one study the two lesion etiology groups displayed no difference in complications including pain, ${ }^{53}$ while another study found pain to be more prevalent in individuals with traumatic compared with non-traumatic lesion etiology. ${ }^{54}$

A significant association between the socioeconomic factor financial difficulties and severity of chronic pain was found. Because of the cross-sectional design of the current study, financial hardship can be both considered as the cause (for example, anxious rumination and catastrophizing on financial problems can exacerbate pain) and the consequence of pain (for example, cost-intensive pain treatments that are not reimbursed by the insurance but lead to shortage in finances). For example, research in general population found low income to be a potential risk and prognostic factor for the development of chronic neck pain. ${ }^{55}$ In contrast, greater vulnerability to pain was found in women with chronic musculoskeletal condition on days when financial worries were experienced. ${ }^{56}$

Finally, multimorbidity is common in individuals with SCI. ${ }^{20}$ The present study revealed a significant association between secondary health conditions (that is, spasticity, contractures, autonomic dysreflexia, urinary tract infection and pressure ulcer) and severity of chronic pain. In general, aggravation of pain due to secondary health conditions has been reported in numerous studies. ${ }^{57}$ However, associations between pain and health conditions are usually complex and bidirectional. For example, spasticity can cause pain (intrinsic spasticity), ${ }^{58,59}$ but pain can also trigger muscle spasms (extrinsic spasticity). ${ }^{60-62}$ Intense pain has been found to activate autonomic dysreflexia, but individuals with autonomic dysreflexia report more painful body locations than individuals with no autonomic dysreflexia. ${ }^{17}$ Although multimorbidity in SCI is challenging to treat, every secondary health condition may represent a potential target to optimize comprehensive pain management.

\section{Limitations}

A number of different limitations need to be considered while interpreting the results of the current study. First, the study design is cross-sectional. Although this allows determining persons at risk based on their sociodemographic and injury-related information, the results do not infer causality concerning socioeconomic factors and secondary health conditions and their relation to pain. Longitudinal analyses are necessary to unravel causal pathways for the development of pain and its chronification. Second, all assessments were based on self-reports. Additional clinical assessments, for example, quantitative sensory testing, or body maps or manikins might increase validity to determine pain type, or pain location, respectively. In general, recommendations concerning pain assessment should be followed (for example, International Spinal Cord Injury Classification, 
International Spinal Cord Injury Pain Basic Data Set, Initiative on Methods, Measurement, and Pain Assessment in Clinical Trials). Finally, the present study focused on biomedical and socioeconomic factors associated with pain. However, with the biopsychosocial model of pain a more heuristic approach to chronic pain is now widely accepted. Therefore, other psychosocial factors should be considered while examining potential causes of pain. For example, depressive symptoms has been found to be a strong determinant of pain prevalence in SCI. ${ }^{2}$

\section{CONCLUSIONS}

Pain is highly prevalent in individuals with SCI living in the Swiss community. Considered at risk for chronic pain are women, older individuals and individuals with financial hardship and specific health conditions that are secondary to SCI. Lacking of satisfactory therapeutic options, especially in the case of neuropathic pain, requires further longitudinal investigation of etiological factors, mechanisms and predictors of chronic pain development in order to support prevention, early detection and treatment of pain in individuals with SCI.

\section{DATA ARCHIVING}

There were no data to deposit.

\section{CONFLICT OF INTEREST}

The authors declare no conflict of interest.

\section{ACKNOWLEDGEMENTS}

This study has been financed in the framework of the Swiss Spinal Cord Injury Cohort Study (SwiSCI, www.swisci.ch), supported by the Swiss Paraplegic Foundation. The members of the SwiSCI Steering Committee are: XJ and Bertrand Léger (Clinique Romande de Réadaptation, Sion); Michael Baumberger and Hans Peter Gmünder (Swiss Paraplegic Center, Nottwil); Armin Curt and Martin Schubert (University Clinic Balgrist, Zürich); Margret Hund-Georgiadis and Kerstin Hug (REHAB Basel, Basel); Hans Georg Koch, (Swiss Paraplegic Association, Nottwil); Hardy Landolt (representative of persons with SCI, Glarus); Hannjörg Koch (SUVA, Luzern); Mirjam Brach, Gerold Stucki (Swiss Paraplegic Research, Nottwil); and Martin Brinkhof and Christine Thyrian (SwiSCI Study Center at Swiss Paraplegic Research, Nottwil).

\section{AUTHOR CONTRIBUTIONS}

Statistical analyses and interpretation of the results were performed by RM and MWGB. RM drafted the manuscript. All authors substantially contributed to the study conception, design and critical revision of the article and gave the final approval of the version to be published. RM confirms that she had full access to the data in the study and final responsibility for the decision to submit for publication.

1 Jensen MP, Hoffman AJ, Cardenas DD. Chronic pain in individuals with spinal cord injury: a survey and longitudinal study. Spinal Cord 2005; 43: 704-712.

2 van Gorp S, Kessels AG, Joosten EA, van Kleef M, Patijn J. Pain prevalence and its determinants after spinal cord injury: a systematic review. Eur J Pain 2015; 19: 5-14.

3 Mehta S, Teasell R, Loh E, Short C, Wolfe D, Hsieh J. Pain Following Spinal Cord Injury. Vancouver: Spinal Cord Injury Rehabilitation Evidence (SCIRE) Project, 2014. Available at: http://www.scireproject.com/sites/default/files/pain management.pdf.

4 Ehde DM, Jensen MP, Engel JM, Turner JA, Hoffman AJ, Cardenas DD. Chronic pain secondary to disability: a review. Clin J Pain 2003; 19: 3-17.

5 Marcondes BF, Sreepathi S, Markowski J, Nguyen D, Stock SR, Carvalho S et al. Pain severity and mobility one year after spinal cord injury: a multicenter crosssectional study. Eur J Phys Rehabil Med (e-pub ahead of print 27 November 2015).

6 Barbetta DC, Lopes AC, Chagas FN, Soares PT, Casaro FM, Poletto MF et al. Predictors of musculoskeletal pain in the upper extremities of individuals with spinal cord injury. Spinal Cord 2015; 54: 145-149.

7 Norrbrink Budh C, Lund I, Ertzgaard P, Holtz A, Hultling C, Levi R et al. Pain in a Swedish spinal cord injury population. Clin Rehabil 2003; 17: 685-690.
8 Klotz R, Joseph PA, Ravaud JF, Wiart L, Barat M. The Tetrafigap Survey on the long-term outcome of tetraplegic spinal cord injured persons: Part III. Medical complications and associated factors. Spinal Cord 2002; 40: 457-467.

9 Wollaars MM, Post MW, van Asbeck FW, Brand N. Spinal cord injury pain: the influence of psychologic factors and impact on quality of life. Clin J Pain 2007; 23: 383-391.

10 Cardenas DD, Bryce TN, Shem K, Richards JS, Elhefni H. Gender and minority differences in the pain experience of people with spinal cord injury. Arch Phys Med Rehabil 2004; 85: 1774-1781.

11 Putzke JD, Richards JS, DeVivo MJ. Predictors of pain 1 year post-spinal cord injury. J Spinal Cord Med 2001; 24: 47-53.

12 Fekete C, Siegrist J, Reinhardt JD, Brinkhof MW. Is financial hardship associated with reduced health in disability? The case of spinal cord injury in Switzerland. PLOS ONE 2014; 9: e90130.

13 Eriks-Hoogland IE, Hoekstra T, de Groot S, Stucki G, Post MW, van der Woude LH. Trajectories of musculoskeletal shoulder pain after spinal cord injury: identification and predictors. J Spinal Cord Med 2014; 37: 288-298.

14 Burchiel KJ, Hsu FP. Pain and spasticity after spinal cord injury: mechanisms and treatment. Spine (Phila Pa 1976) 2001; 26: S146-S160.

15 Tekin L, Yilmaz B, Alaca R, Ozcakar L, Dincer K. Coccyx fractures in patients with spinal cord injury. Eur J Phys Rehabil Med 2010; 46: 43-46.

16 Widerstrom-Noga EG, Turk DC. Exacerbation of chronic pain following spinal cord injury. J Neurotrauma 2004; 21: 1384-1395.

17 Widerstrom-Noga E, Cruz-Almeida Y, Krassioukov A. Is there a relationship between chronic pain and autonomic dysreflexia in persons with cervical spinal cord injury? J Neurotrauma 2004; 21: 195-204.

18 Dijkers M, Bryce T, Zanca J. Prevalence of chronic pain after traumatic spinal cord injury: a systematic review. J Rehabil Res Dev 2009; 46: 13-29.

19 Rubinelli S, Glaessel A, Brach M. Special issue SwiSCl: from the person's perspective: perceived problems in functioning among individuals with spinal cord injury in Switzerland. J Rehabil Med 2016; 48: 235-243.

20 Brinkhof WMG, Al-Khodairy A, Eriks-Hoogland I, Fekete C, Hinrichs T, Hund-Georgiadis M et al. Health conditions in people with spinal cord injury: contemporary evidence from a population-based community survey in Switzerland. J Rehabil Med 2015; 48: 197-209.

21 Post MW, Brinkhof MW, von Elm E, Boldt C, Brach M, Fekete C et al. Design of the Swiss Spinal Cord Injury Cohort Study. Am J Phys Med Rehabil 2011; 90: S5-16.

22 Brinkhof M, Fekete C, Chamberlain J, Post M, Gemperli A, SwiSCl Study Group. Swiss national community survey on functioning after spinal cord injury: protocol, characteristics of participants and determinants of non-response. J Rehab Med 2016; 48: $120-130$

23 Fekete C, Segerer W, Gemperli A, Brinkhof MW. Participation rates, response bias and response behaviours in the community survey of the Swiss Spinal Cord Injury Cohort Study (SwiSCI). BMC Med Res Methodol 2015; 15: 5-14.

24 DeVivo MJ, Biering-Sorensen F, New P, Chen Y. Standardization of data analysis and reporting of results from the International Spinal Cord Injury Core Data Set. Spinal Cord 2011; 49: 596-599.

25 Hinrichs T, Prodinger B, Brinkhof M, Gemperli A, SwiSCl Study Group. Subgroups in epidemiological studies on spinal cord injury: evaluation of international recommendations in the Swiss Spinal Cord Injury Cohort Study. J Rehab Med 2016; 48: 141-148.

26 Kalpakjian CZ, Scelza WM, Forchheimer MB, Toussaint LL. Preliminary reliability and validity of a spinal cord injury secondary conditions scale. J Spinal Cord Med 2007; 30: 131-139.

27 Swiss Household Panel Lausanne: Swiss Centre of Expertise in the Social Sciences. 2014. Available at: http://forscenter.ch/de/our-surveys/schweizer-haushalt-panel/. Accessed 2016.

28 Widerstrom-Noga E, Biering-Sorensen F, Bryce T, Cardenas DD, Finnerup NB, Jensen MP et al. The international spinal cord injury pain basic data set. Spinal Cord 2008; 46: 818-823.

29 Forchheimer MB, Richards JS, Chiodo AE, Bryce TN, Dyson-Hudson TA. Cut point determination in the measurement of pain and its relationship to psychosocial and functional measures after traumatic spinal cord injury: a retrospective model spinal cord injury system analysis. Arch Phys Med Rehabil 2011; 92: 419-424.

30 Brant R. Assessing proportionality in the proportional odds model for ordinal logistic regression. Biometrics 1990; 46: 1171-1178.

31 Xing L. Fitting stereotype logistic regression models for ordinal response variables in educational research (Stata). J Mod Appl Stat Meth 2014; 13: 528-545.

32 Stekhoven DJ, Buhlmann P. MissForest - non-parametric missing value imputation for mixed-type data. Bioinformatics 2012; 28: 112-118.

33 Turner JA, Cardenas DD, Warms CA, McClellan CB. Chronic pain associated with spinal cord injuries: a community survey. Arch Phys Med Rehabil 2001; 82: 501-509.

34 Ullrich PM, Jensen MP, Loeser JD, Cardenas DD. Pain intensity, pain interference and characteristics of spinal cord injury. Spinal Cord 2008; 46: 451-455.

35 Siddall PJ, McClelland JM, Rutkowski SB, Cousins MJ. A longitudinal study of the prevalence and characteristics of pain in the first 5 years following spinal cord injury. Pain 2003; 103: 249-257.

36 Finnerup NB, Attal N, Haroutounian S, McNicol E, Baron R, Dworkin RH et al. Pharmacotherapy for neuropathic pain in adults: a systematic review and meta-analysis. Lancet Neurol 2015; 14: 162-173.

37 Finnerup NB, Norrbrink C, Trok K, Piehl F, Johannesen IL, Sorensen JC et al. Phenotypes and predictors of pain following traumatic spinal cord injury: a prospective study. J Pain 2014; 15: 40-48.

38 Finnerup NB, Faaborg P, Krogh K, Jensen TS. Abdominal pain in long-term spinal cord injury. Spinal Cord 2008; 46: 198-203. 
39 Mahnig S, Landmann G, Stockinger L, Opsommer E. Pain assessment according to the International Spinal Cord Injury Pain classification in patients with spinal cord injury referred to a multidisciplinary pain center. Spinal Cord 2016; 54: 809-815.

40 Ness TJ. Chronic abdominal, groin, and perineal pain of visceral origin. In: Wilson P, Haddox D, Jensen TS (eds). Textbook of Clinical Pain Management Chronic Pain, Vol. 3. Arnold: London, England, 2003, pp 567-586.

41 Faaborg PM, Finnerup NB, Christensen P, Krogh K. Abdominal pain: a comparison between neurogenic bowel dysfunction and chronic idiopathic constipation. Gastroenterol Res Pract 2013; 2013: 1-7.

42 Kogos SC Jr, Richards JS, Banos JH, Ness TJ, Charlifue SW, Whiteneck GG et al. Visceral pain and life quality in persons with spinal cord injury: a brief report. J Spinal Cord Med 2005; 28: 333-337.

43 Miro J, Gertz KJ, Carter GT, Jensen MP. Pain location and functioning in persons with spinal cord injury. PM R 2014; 6: 690-697.

44 Werhagen L, Budh CN, Hultling C, Molander C. Neuropathic pain after traumatic spinal cord injury-relations to gender, spinal level, completeness, and age at the time of injury. Spinal Cord 2004; 42: 665-673.

45 Simons LE, Elman I, Borsook D. Psychological processing in chronic pain: a neural systems approach. Neurosci Biobehav Rev 2014; 39: 61-78.

46 Gagliese L. Pain and aging: the emergence of a new subfield of pain research. J Pain 2009; 10: 343-353.

47 Molton I, Cook KF, Smith AE, Amtmann D, Chen WH, Jensen MP. Prevalence and impact of pain in adults aging with a physical disability: comparison to a US general population sample. Clin J Pain 2014; 30: 307-315.

48 Widerstrom-Noga E, Finlayson ML. Aging with a disability: physical impairment, pain and fatigue. Phys Med Rehabil Clin N Am 2010; 21: 321-337.

49 Hitzig SL, Campbell KA, McGillivray CF, Boschen KA, Craven BC. Understanding age effects associated with changes in secondary health conditions in a Canadian spinal cord injury cohort. Spinal Cord 2010; 48: 330-335.

50 Spungen AM, Adkins RH, Stewart CA, Wang J, Pierson RN Jr, Waters RL et al. Factors influencing body composition in persons with spinal cord injury: a cross-sectional study. J Appl Physiol (1985) 2003; 95: 2398-2407.
51 Bauman W, Spungen A. Body composition in aging: adverse changes in ablebodied persons and in those with spinal cord injury. Top Spinal Cord Inj Rehabil 2001; 6: 22-36.

52 New PW, Simmonds F, Stevermuer T. A population-based study comparing traumatic spinal cord injury and non-traumatic spinal cord injury using a national rehabilitation database. Spinal Cord 2011; 49: 397-403.

53 Cosar SN, Yemisci OU, Oztop P, Cetin N, Sarifakioglu B, Yalbuzdag SA et al. Demographic characteristics after traumatic and non-traumatic spinal cord injury: a retrospective comparison study. Spinal Cord 2010; 48: 862-866.

54 Ones K, Yilmaz E, Beydogan A, Gultekin O, Caglar N. Comparison of functional results in non-traumatic and traumatic spinal cord injury. Disabil Rehabil 2007; 29: 1185-1191.

55 Palmlof L, Skillgate E, Alfredsson L, Vingard E, Magnusson C, Lundberg M et al. Does income matter for troublesome neck pain? A population-based study on risk and prognosis. J Epidemiol Community Health 2012; 66: 1063-1070.

56 Rios R, Zautra AJ. Socioeconomic disparities in pain: the role of economic hardship and daily financial worry. Health Psychol 2011; 30: 58-66.

57 Jensen MP, Truitt AR, Schomer KG, Yorkston KM, Baylor C, Molton IR. Frequency and age effects of secondary health conditions in individuals with spinal cord injury: a scoping review. Spinal Cord 2013; 51: 882-892.

58 Levi R, Hultling C, Seiger A. The Stockholm Spinal Cord Injury Study: 2. Associations between clinical patient characteristics and post-acute medical problems. Paraplegia 1995; 33: 585-594.

59 Skold C, Levi R, Seiger A. Spasticity after traumatic spinal cord injury: nature, severity, and location. Arch Phys Med Rehabil 1999; 80: 1548-1557.

60 Decq P. Pathophysiology of spasticity. Neurochirurgie 2003; 49: 163-184.

61 St George CL. Spasticity. Mechanisms and nursing care. Nurs Clin North Am 1993; 28 : 819-827.

62 Sheean G. The pathophysiology of spasticity. Eur J Neurol 2002; 9: 3-9.

63 Hagenaars AK, de Vos K, Zaidi MA. Poverty Statistics in the Late 1980s: Research Based on Micro-data. Office for Official Publications of the European Communities: Luxembourg, 1994. 